\title{
Mais sonetos de Shakespeare
}

\author{
Renata Cordeiro
}

\section{SONNET 9}

Is it for fear to wet a widow's eye

That thou consum'st thyself in single life?

Ah! if thou issueless shalt hap to die,

The world will wail thee like a makeless wife;

The world will be thy widow and still weep

That thou no form of thee hast left behind,

When every private widow well may keep

By children's eyes, her husband's shape in mind.

Look, what an unthrift in the world doth spend

Shifts but his place, for still the world enjoys it;

But beauty's waste hath in the world an end,

And kept unus'd the user so destroys it.

No love toward others in that bosom sits

That on himself such murderous shame commits. 
CORDEIRO, Renata. Mais sonetos de Shakespeare

\section{SONETO 9}

Tens tu medo de ver a viúva a carpir

E consomes a vida assim desirmanada?

Ah! Se um dia sem prole acabas por partir,

Chora-te o mundo, igual à esposa abandonada;

Como viúva, tens o mundo a prantear

A tua morte, sem a imagem' the deixares,

Enquanto sabem, sim, as viúvas guardar

Vivo o marido, ali, nos filiais olhares. ${ }^{2}$

O que um pródigo, aqui no mundo, malbarata,

Só muda de lugar e o mundo disso frui;

Mas tem fim a beleza, a qual se desbarata

Neste mundo, e sem uso o usuário a derrui.

amor pelo outro em meio ao coração não sente

Quem a si assassina, e vergonhosamente. 


\section{SONNET 10}

For shame deny that thou bear'st love to any,

Who for thyself art so unprovident!

Grant if thou wilt, thou art belov'd of many,

But that thou none lov'st is most evident:

For thou art so possessed with murderous hate,

That 'gainst thyself thou stick'st not to conspire,

Seeking that beauteous roof to ruinate

Which to repair should be thy chief desire.

$O$ change thy thought, that I may change my mind!

Shall hate be fairer lodged than gentle love?

Be as thy presence is, gracious and kind,

Or to thyself at least kind-hearted prove:

Make thee another self for love of me,

That beauty still may live in thine or thee. 
CORDEIRO, Renata. Mais sonetos de Shakespeare

\section{SONETO 10}

Dizes, vergonha!, não amar, não, a ninguém,

Tu, que és para ti nem um pouco precavido!

Admitirei que a ti diversos querem bem,

Mas que não tens amor a ninguém, é sabido:

Pois te possui um ódio, uma raiva assassina, ${ }^{3}$

E tramas, incessante, o que te vai ferir,

Tentando pôr a casa ${ }^{4}$ esplêndida em ruína,

A qual devias bem querer reconstruir:

Muda de idéia, e mudo a minha opinião! 5

Deve o ódio morar mais lindamente que o amor?

Sê belo e gentil, qual a tua compleição,

Ou, pelo menos, sê contigo encantador:

Faze outro tu de ti, por teu amor a mim,

E que em ambos, jamais, o Belo tenha fim. 


\section{SONNET 11}

As fast as thou shalt wane, so fast thou grow'st

In one of thine from that which departest;

And that fresh blood which youngly thou bestow'st

Thou mayst call thine when thou from youth convertest:

Herein lives wisdom, beauty, and increase;

Without this, folly, age, and cold decay:

If all were minded so, the times should cease,

And threescore year would make the world away.

Let those whom Nature hath not made for store,

Harsh, featureless, and rude, barrenly perish:

Look, whom she best endowed, she gave the more;

Which bounteous gift thou shouldst in bounty cherish:

She carved thee for her seal, and meant thereby

Thou shouldst print more, not let that copy die. 
CORDEIRO, Renata. Mais sonetos de Shakespeare

\section{SONETO 11}

Depressa crescerás, decrescente fugaz,

Num filho teu de quem, por fim, te apartarás;

E quanto sangue tu lhe outorgues, em rapaz,

Quando velho, dizê-lo teu, tu poderás:

Nele haverá juízo, o Belo, e crescimento;

Sem o quê, senectude, insânia, queda fria:

Se se pensasse assim, teriam fim os tempos,

Em sessenta anos, todo o mundo acabaria.

O que a Natura fez para não florescer,

Rude, estéril, feioso, haverá de findar:

Mas aos perfeitos, quis, desejou conceder;

Bondade que com grande apreço hás de pagar:

A Natura gravou em ti Seu próprio selo:

Faze cópias, mantém-te com vida, ó modelo. ${ }^{6}$ 


\section{SONNET 12}

When I do count the clock that tells the time,

And see the brave day sunk in hideous night;

When I behold the violet past prime,

And sable curls o'er-silver'd all with white;

When lofty trees I see barren of leaves,

Which erst from heat did canopy the herd,

And summer's green, all girded up in sheaves

Borne on the bier with white ant bristly beard,

Then of thy beauty do I question make,

That thou among the wastes of Time must go,

Since sweets and beauties do themselves forsake,

And die as fast as they see others grow;

And nothing 'gainst Time's scythe can make defence

Save breed to brave him when he takes thee hence. 
CORDEIRO, Renata. Mais sonetos de Shakespeare

\section{SONETO 12}

Quando soa o relógio e conto cada hora,

E vejo em noite horrenda o dia alvo afundar;

E da flor violeta o seu Abril de outrora, ${ }^{7}$

E cachos de azeviche, argênteos a branquear;

E sem folhas, eu vejo altíssimos ramados,

Que eram, quando calor, os toldos da manada,

E o verde do estio, iá por sarmentos cercados,

A ir-se no caixão, com barba alva e embotada,

Ponho-me a perguntar pela tua beleza,

Que a ruína do Tempo irá, sim, atingir,

Desamparadas hão de estar graças, lindeza,

Morrendo, ao entrever os novos a florir;

Só te defenderá da foice do grão Tempo,

Quando vier ceifar-te aqui, o teu rebento. 


\section{SONNET 13}

O that you were your self; but, love, you are No longer yours than you yourself here live; Against this coming end you should prepare, And your sweet semblance to some other give. So should that beauty which you hold in lease Find no determination; then you were Your self again after yourself's decease, When your sweet issue your sweet form should bear. Who lets so fair a house fall to decay, Which husbandry in honour might uphold Against the stormy gusts of winter's day And barren rage of death's eternal cold?

$\mathrm{O}$, none but unthrifts: dear my love you know: You had a father; let your son say so. 
CORDEIRO, Renata. Mais sonetos de Shakespeare

\section{SONETO 13}

Ah! Dependêreis só de vós ${ }^{8}$ mas, meu amado

Dependeis só de vós enquanto estais com vida;

E contra o fim, deveis estar bem preparado,

E legar aos que vêm a imagem ${ }^{9}$ tão querida.

O Belo, ${ }^{10}$ que vos foi cedido por um tempo,

Nunca terminará; podeis voltar a ser

Tal qual anteriormente, após o passamento,

Quando a perfeita forma a prole receber.

Quem deixará cair tão linda habitação, ${ }^{11}$

Se a puder sustentar uma gestão ${ }^{12}$ honrosa

Contra esses furacões da gélida estação,

E o ódio estéril da morte eterna e borrascosa?

Oh, que pródigo! Amor, tivestes pai outrora:

Que o vosso filho assim vos trate desde agora. 


\section{SOBRE A TRADUTORA}

Renata Cordeiro é filósofa, prolífica tradutora e pós-graduada em tradução pela USP. Entre suas traduções destaca-se a premiada Histórias ou contos de outrora, de Charles Perrault, pela editora Landy. A mesma editora lançou em 2004 Sonetos ao jovem desconhecido, com suas traduções de Shakespeare, e deve lançar, no início de 2007, o primeiro livro da própria Renata: O sonho do unicórnio.

\section{NOTAS}

1 Form, no original: possível referência ao conceito escolástico de algo que contém o "princípio essencial determinante".

2 Na doutrina neoplatônica, os olhos eram considerados as "janelas da alma".

3 Aqui, Shakespeare continua a usar um vocabulário - vergonha, assassina - que já empregara no dístico do soneto anterior: "O amor pelo outro em meio ao coração não sente/Quem a si assassina, e vergonhosamente." Também no Soneto 6, Shakespeare usa a expressão self-killed. Todas essas referências querem ressaltar o processo de autodestruição pelo qual o jovem passa quando se nega a procriar.

4 Roof, telhado. Aqui: (1) cabeça, por sinédoque o corpo todo; (2) casa, por sinédoque a família.

5 É a primeira vez que Shakespeare (ou a persona) alude a si próprio.

6 O "grande selo" que a Natureza grava (carve) nas suas mais altas criações as valida e thes confere autenticidade, como o monarca o faz ao gravar o seu selo nos documentos do Estado.

7 Shakespeare retoma aqui os temas dos sonetos 5, 6 e 7, valendo-se do livro XV das Metamorfoses de Ovídio. Nos versos 3 e 4, particularmente, o Bardo se vale de outra obra do mesmo autor, A Arte de Amar, livro Il: "A beleza é um bem frágil: tudo o que se lhe acrescenta com os anos a diminui; ela murcha com o tempo; nem as violetas, nem os lírios abrem a corola em flor, e, uma vez caída a rosa, o espinho se ergue por si só. Também, belo adolescente, terás logo os cabelos brancos, terás as rugas que o tempo sulca."

8 Este é o primeiro soneto em que Shakespeare trata o jovem por you em vez de thou. $O$ thou dos sonetos precedentes deve ser considerado como mais enfático do que o you.

9 Há aqui a implicação de que essa imagem perpetuaria tanto a parte espiritual quanto a física do you.

10 O Belo interior e exterior.

11 Corpo; família.

12 Husbandry é aqui usado com o sentido de boa administração, gestão, governo, aludindo também a casamento (to husband é o verbo desposar, e husband é o substantivo esposo, marido). 